\title{
Analysis of the Mediating Role of Psychological Empowerment in Perceived Trust and Work Performance
}

\author{
Xiaoli LIU* and Xiaopeng REN
}

CAS Key Laboratory of Behavioral Science, Institute of Psychology, Chinese Academy of Sciences, Beijing 100101, China

* Correspondence: mxuv27@163.com

\begin{abstract}
As a potential motivation, psychological empowerment stimulates employees' work behaviors, and it determines the degree of effort and duration of employees' work. Only when employees are psychologically empowered, will they have an impact on their behavior when they believe that they are trusted. This paper chose to set the independent variable as the employee's perceived trust and the dependent variable as the company's work performance, and explored the mediating role of psychological empowerment in the two. The psychological empowerment of employees had a positive impact on work performance. Employees with high psychological empowerment tended to be proactive in their work, and had more input in the work, which in turn encouraged employees to have higher work performance. The four dimensions of psychological empowerment can positively affect employee task performance, and the ability and influence of psychological empowerment had a positive impact on relationship performance. Psychological empowerment as a whole perception played a part of the mediating role between the perception of superior dependency and task performance, and it played a part of the mediating role between perception of superior dependency and relationship performance. As a whole perception, psychological empowerment played a part of mediating role between perceived information disclosure and task performance, and part of mediating role between perceived information disclosure and relationship performance. In the study of perceived trust and work performance, this article focused on the mediating role of psychological empowerment, and further understood the internal mechanism of perceived trust.
\end{abstract}

Keywords: Perceived Trust; Psychological Empowerment; Work Performance; Perceived Information Disclosure; Perceived Superior Dependence

\section{Introduction}

Establishing trust within the organization can reduce management costs, improve organizational efficiency, improve employee perception of authorization, and promote cooperation among members of the organization, which helps to enhance the cohesion of the organization and the team ${ }^{[1-4]}$. Conger and Kanungo ${ }^{[5]}$ transferred the concept of authorization from management practice to the perception level of subordinates. They believed that authorization is the intrinsic motivational concept of employees' self-efficacy. This definition laid the foundation for psychological authorization. Kraimer believes that psychological empowerment is a set of internal motivation that stimulates employees' work behavior, which determines the degree of effort and duration of employees' work ${ }^{[6]}$. Chinese scholar Li Chaoping draws on Spreitzer's point of view and believes that psychological empowerment is the comprehensive cognition of employees on their job meaning, ability, autonomy and influence ${ }^{[7]}$. Lei Qiaoling ${ }^{[8]}$ believes that psychological empowerment includes an internal state and a comparative state. The internal state is an individual's cognition of one's own work meaning and work ability. When an employee thinks that the work is in line with his own value expectations, he will think that the work is more meaningful; when the employee thinks that he is capable of meeting the 
requirements of the job, his sense of self-efficacy will increase and it is easier to stimulate his inner work motivation. When employees control the work process and complete the work arrangements independently, the employee's autonomous decision-making power will be satisfied, which will reduce the employee's negative emotions and enhance the employee's work vitality[9-11].

The impact of psychological empowerment on organizations mainly includes organizational citizenship behavior, innovation performance and work performance. When $\mathrm{Wu}$ Zhiming found that the work meaning and ability in the psychological empowerment dimension are positively correlated with employees' organizational citizenship behavior ${ }^{[12]}$. Bowen found that psychological empowerment affects employees' innovative behaviors, especially when employees are faced with complex, uncertain and ambiguous jobs ${ }^{[13]}$. When Wang Guomeng studied the impact, he found that psychological empowerment can effectively predict task performance and peripheral performance ${ }^{[14]}$. The autonomy, self-efficacy and influence of knowledge workers are significantly related to task performance, and work meaning, autonomy and influence are significantly related to relationship performance. Chen Hong analyzed the psychological empowerment of new employees in many first-tier cities in China, and analyzed the impact of psychological empowerment on their work, and found positive results ${ }^{[15]}$.

The first part of this article is the introduction. The research direction of this article is determined by combing the research background and relevant domestic and foreign documents. The second part is the theoretical foundation part. A review of related theories provides a scientific basis and mechanism of action for the study of this article. The third part builds a research model based on the theoretical foundation and puts forward the research hypothesis among variables. The fourth part is the design of the research plan, which forms the questionnaire of this research. The collected questionnaire data is analyzed using SPSS20.0 software, and the validity of the theoretical model and research hypothesis is explored through data analysis. The last part is the analysis of statistical results. Based on relevant theoretical research and empirical analysis, the corresponding analysis were made.

This article explores the mechanism of perceived trust, which has contributed to the development of the theory of interpersonal trust; the introduction of intrinsic work motivation and self-evaluation perspectives is a new supplementary method to explain the mechanism of perceived trust. In the study of perceived trust and work performance, this article focuses on the mediating role of psychological empowerment, and further understands the internal mechanism of perceived trust.

\section{Related Theoretical Basis}

\subsection{Psychological Empowerment}

There are two main paths for the research of delegation theory. One path is to give the subordinates the power in the superiors, so that the subordinates can fully grasp the resources and have the power to make decisions, which is called relationship authorization. Another way is to explore the psychological perception of authorization from the perspective of employees, that is, psychological authorization. Psychological empowerment explores the perception and behavior of empowerment from the perspective of employees' intrinsic motivation. Scholars who study authorization from the perspective of employees believe that authorization reflects the psychological state of employees. When power is transferred to employees, if the employee does not act as expected, there are only two possibilities. One is that the employee does not realize that they have power, and the other is that they feel powerless about the matter. In this case, psychological empowerment is a psychological variable that involves employees' internal self-recognition.

This article focuses on the mediating role of psychological empowerment in the research of perceived trust and work performance. Thomas's definition ${ }^{[16]}$ of psychological empowerment is also based on intrinsic work motivation. Therefore, this article adopts Thomas' definition of psychological empowerment, that is, psychological empowerment 
is a composite of employees' perception of their own ability to control work, influence various aspects of the organization, and their perception of self-worth and ability to complete work.

\subsection{Perceived Trust}

There are three main viewpoints in the existing research on trust. The first view regards trust as an expectation and belief. Costigan believes that trust is an individual's positive beliefs about the other party, and based on this belief that the other party's behavior will bring positive results to oneself[17]. The second view ${ }^{[18]}$ is that trust is a kind of will. The third view is that trust is a risky behavior. Its manifestation is the individual's choice behavior in the dilemma of trust, which mainly includes behaviors such as risk aversion, cooperation and altruism. The formation of a trust relationship requires the participation of the trusting giver and the perceiving party, and is the result of mutual interaction between the two parties. Although trust and perceived trust are often mentioned, they are independent constructs. In the process of forming a trust relationship, the trusting parties may have different attitudes and behaviors due to different perceptions of trust.

This article adopts the definition of perceived trust made by Lau ${ }^{[19]}$ when exploring the mechanism of perceived trust based on the Chinese background. Perceived trust is the perception that employees autonomously feel their superiors' trust in themselves, is the reliance on superiors in their psychological cognition and the resulting perception of spontaneous compliance with the agreement to achieve the willingness to cooperate.

\subsection{Work Performance}

International scholars have focused their work on three levels of work performance: individual performance, team performance and organizational performance: individual performance, team performance and organizational performance ${ }^{[20]}$. The focus of individual performance is the individual employees in the organization, and the work performance of individual employees in the organization is discussed. Team performance studies the team as a whole and pays attention to the overall performance of the team ${ }^{[21-23]}$. Organizational performance is based on the overall organization as the research object, focusing on the overall performance of the organization. This article takes the employees in the organization as the research object, and is devoted to discussing the influence mechanism of individual level work performance.

This article further recognizes that work performance is reflected by the behavior and results of employees. The comprehensive view oriented by behavior and result covers various factors of attitude, behavior, ability and result, and realizes the unification and integration of implicit and explicit, as well as process and result. Therefore, this article adopts Borman's definition ${ }^{[24]}$ of work performance, that is, work performance is the behavior and output shown by employees at work that can help the company achieve business goals.

\subsection{Theory of Intrinsic Work Motivation}

Employees who have a strong pursuit of challenge and mastery, participate in work to experience the sense of competence at work. This is a kind of intrinsic efficiency motivation, which has idiosyncratic and persistent characteristics. The above definition emphasizes the internal determinants of individual motivation, and competency and selfdetermination are the core components of internal work motivation ${ }^{[25]}$. Existing studies have shown that the role of employees' intrinsic work motivation depends not only on individual differences, but also on the impact of the work environment. Therefore, intrinsic work motivation has the characteristics of individuality and sociality ${ }^{[26]}$. Intrinsic work motivation, as an endogenous state of the individual, depends on the employee's preferences, experience and cognition of the environment. Its production should never be disturbed by the management mode of the enterprise, but this series of comprehensive effects will cause changes in the work motivation of the employees themselves. Trust from 
superiors can strengthen communication, provide opportunities for effective problem solving, and give employees more recognition and autonomy ${ }^{[27]}$. This will enhance the employees' intrinsic work motivation, which will produce a higher sense of competence, autonomy and belonging, and enhance employees' recognition of work value, which will further enhance employees' intrinsic work motivation and psychological empowerment perception.

\section{Psychological Empowerment Intermediary Model Construction}

\subsection{Theoretical Model}

In the two-dimensional relationship between superiors and superiors, employees who perceive trust will get more emotional input, support and dependence from superiors. This will increase the employees' intrinsic motivation to work and enable them to obtain higher psychological acceptance, which in turn affects their work behavior and performance ${ }^{28,29]}$. Therefore, the research model of this article aims to explore the relationship between employees' perceived trust, psychological empowerment and work performance in the context of organizational management.

This paper refers to the trust behavior scale of Gillespie in terms of dimension division, and divides employee perception trust into two dimensions: perception of superior dependence and perception of information disclosure. Employees' perception of psychological empowerment comes from their inner work motivation and self-perception. Therefore, referring to the psychological empowerment model constructed by Spreitzer ${ }^{[30]}$ based on intrinsic work motivation, psychological empowerment is divided into work meaning, ability, autonomy and influence. The impact on employees' work performance is mainly considered from the two aspects of behavior and results. Therefore, this article summarizes the research direction of work limit into task performance and relationship performance. This paper combines the two-dimensional management scenarios of the upper and lower levels in the organization to construct a theoretical model, as shown in Figure 1.

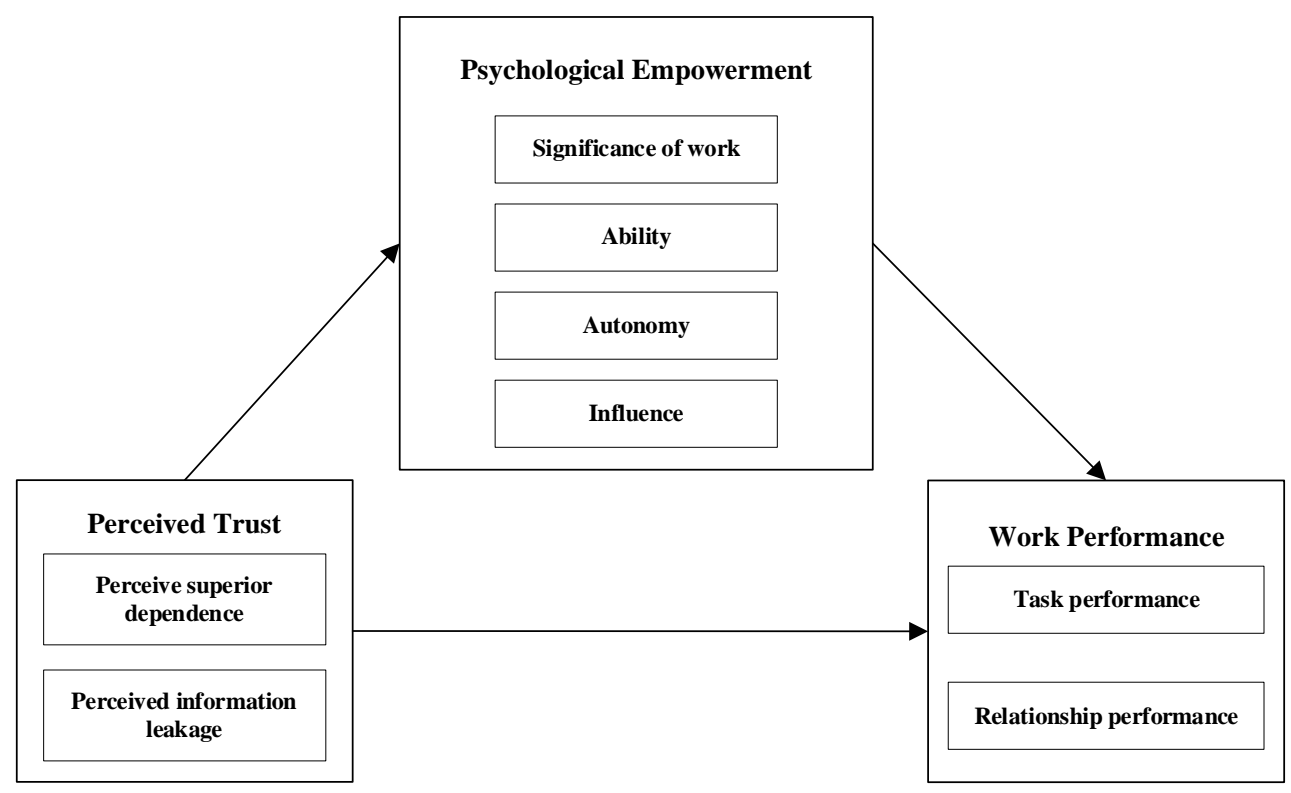

Figure 1. Construction of the Intermediary Model of Psychological Empowerment in Perceived Trust and Work Performance.

This article sets the independent variable as $\mathrm{X}$, the dependent variable as $\mathrm{Y}$, and the intermediate variable as $M$ to facilitate the analysis and understanding below ${ }^{[31,32]}$. The first step is to explore whether the coefficient $a$ in the regression analysis of $X$ versus $M$ is significant. If it is not significant, stop the mediation test, and if it is significant, proceed to the next step. The second step is to verify whether the coefficient $b$ in the regression analysis of $M$ versus $\mathrm{Y}$ is significant. If it is not significant, stop the mediation test; if it is 
significant, proceed to the next step. The third step is to introduce $X$ and $M$ into the regression equation to explore the common influence of $\mathrm{X}$ and $\mathrm{M}$ on $\mathrm{Y}$. If the regression coefficient $c$ of $X$ is significant, and the regression coefficient $\mathrm{d}$ of $\mathrm{M}$ is significant, it indicates that $M$ plays a part of the mediating role. If the regression coefficient $c$ of $X$ is significant, the regression system $\mathrm{d}$ of $\mathrm{M}$ is not significant, indicating that $\mathrm{M}$ plays a completely mediating role. If the regression coefficient $\mathrm{c}$ of $\mathrm{X}$ is not significant, the Soble test needs to be performed. If the Soble test is significant, it means that $\mathrm{M}$ plays a completely mediating role. If the Soble test is not significant, it means that there is no mediating effect. The specific situation is shown in Figure 2.

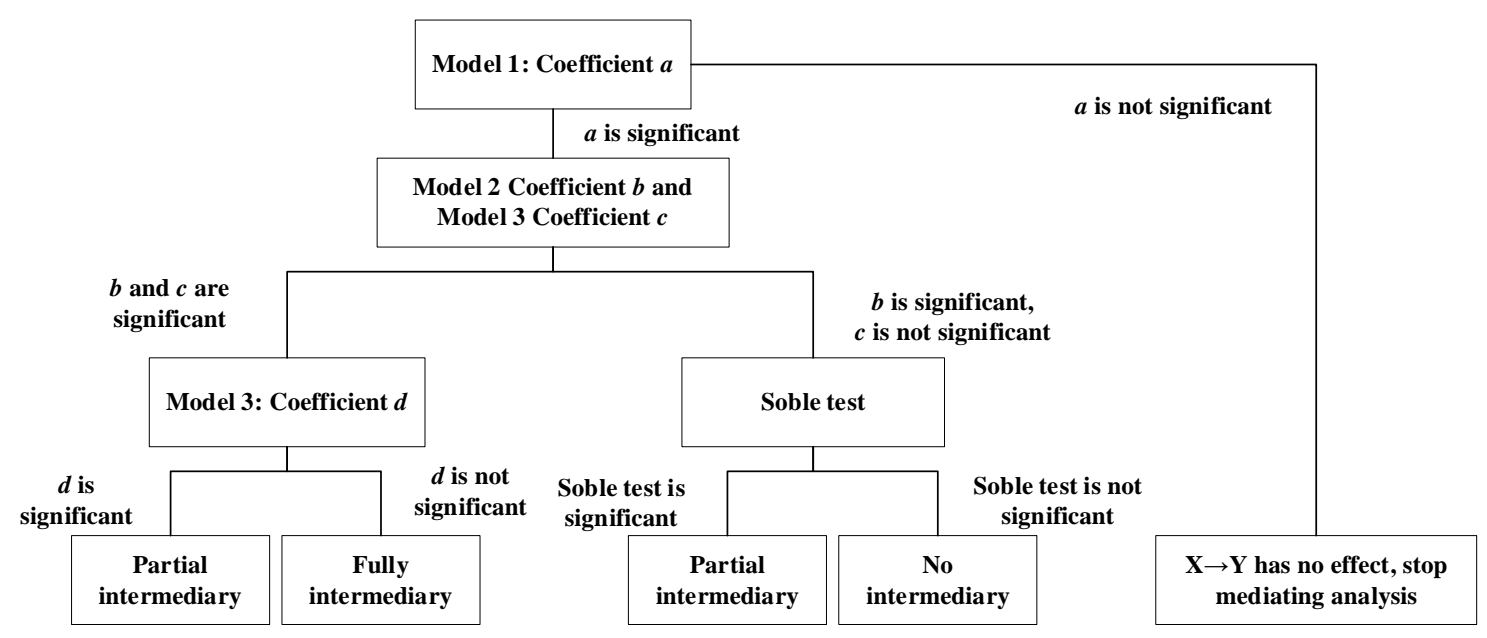

Figure 2. Test of Intermediary Effect.

\subsection{Hypothesis of the Relationship between Psychological Empowerment and Work Performance}

In work situations, employees tend to have a stronger sense of competence and autonomy, and focus on the impact and value of the work itself. The employees with a high sense of psychological empowerment will respond autonomously, take active actions, and strive to coordinate resources when faced with risks and uncertainties in the work, and have high work performance ${ }^{[33]}$. Studies have shown that psychological empowerment is related to the effectiveness of management and the work performance of employees. Employees who are more influential at work can coordinate resources more smoothly when completing tasks, organize that row of work, and generate high work performance. Therefore, this article perceives that employees who are psychologically empowered will have better performance:

H1: Psychological empowerment positively affects the work performance of employees.

H1a: The meaning of work positively affects employee task performance.

H1b: Ability positively affects employee task performance.

H1c: Autonomy positively affects employee task performance.

H1d: Influence is positively affecting employee task performance.

H1e: The meaning of work positively affects employee relationship performance.

H1f: Ability positively affects employee relationship performance.

H1g: Autonomy positively affects employee relationship performance.

H1h: Influence positively affects employee relationship performance.

\subsection{Mediation Hypothesis of Psychological Empowerment in Perceived Trust and Work Performance}

The trust between the superior and the superior creates a unique atmosphere for the authorization practice, which leads to the realization of the organization's goals. Employees who perceive trust will get personalized information related to their work performance, and they will get more reliance and support ${ }^{[34]}$. This in itself creates an 
environment of psychological empowerment, in this environment, there will be more exchanges and communication between employees and their superiors, and work towards a common goal.

Based on the internal work motivation and self-assessment point of view, when employees perceive the trust of their superiors, they will positively evaluate themselves, thereby giving employees psychological empowerment. In order to maintain this kind of psychological empowerment, employees who perceive trust will strive to improve their Work performance ${ }^{[35]}$. This article believes that perceived trust can help increase employees' psychological empowerment, and that the increase of psychological empowerment will enable employees to have better performance. Therefore, the following assumptions are made:

H2: Psychological empowerment plays an intermediary role in employee perception of trust and Work performance.

H2a: Psychological empowerment plays an intermediary role in employees' perception of superior dependence and task performance.

H2b: Psychological empowerment plays an intermediary role in employees' perception of superior dependence and relationship performance.

H2c: Psychological empowerment plays an intermediary role in employee perception information disclosure and task performance.

H2d: Psychological empowerment plays an intermediary role in employee perception of information disclosure and relationship performance.

\section{Scheme Design}

\subsection{Questionnaire}

The survey questionnaire designed in this article contains four parts. The first part is the research description of the questionnaire, including the basic information of the participants in the questionnaire. It consists of 6 question groups. The second part is the measurement of perception trust, which contains 10 items in total, among which 5 items are dependent on the superior level of perception, and 5 items are revealed by perception information. The third part is the measurement of psychological empowerment. It contains 12 items, including 3 items for work significance, 3 items for ability, 3 items for selfdetermination, and 3 items for influence. The fourth part is the measurement of Work performance. It contains 11 items, including 5 items on task performance and 6 items on relationship performance.

The survey subjects selected in this article are mainly employees of different enterprises and institutions.

Firstly, this article selects MBA students who have participated in actual work in enterprises and institutions. They come from different industries and regions, which makes the sample highly reliable and rich. A total of 110 survey questionnaires were distributed and 101 survey questionnaires were returned.

Secondly, relying on Internet social platforms-"WeChat" and "QQ" to distribute questionnaires to classmates, friends, etc. participating in the work, a total of 207 questionnaires were distributed and recovered.

The questionnaire was issued from June 2021 to August 2021. A total of 317 questionnaires were distributed and 308 sample questionnaires were collected. The sample recovery rate was $97.2 \%$. After removing 21 invalid questionnaires, 287 questionnaires were obtained, and the recovery rate of valid sample questionnaires was $90.5 \%$.

\subsection{Descriptive Statistical Analysis}

From Table 1, it can be seen that the proportion of "female" in the sample is $52.96 \%$, and the proportion of male samples is $47.04 \%$, and the ratio of males to females is not much different. In terms of age, there are relatively more "26-30 years old" in the sample, with a proportion of $45.99 \%$. From the perspective of educational background, $49.48 \%$ of the samples choose "undergraduate", and $35.19 \%$ of the samples are masters and above. 
From the perspective of Work distribution, most of the samples are "general employees", with a ratio of $58.54 \%$. Judging from the distribution of working years of enterprises, most of the samples are "1-3 years", with a total of 138 persons accounting for $48.08 \%$, and $30.31 \%$ of the samples are 4-6 years. In the sample, the proportion of "private enterprises" is the largest, at $48.43 \%$.

Table 1. Descriptive Statistics of Basic Information.

\begin{tabular}{|c|c|c|c|}
\hline Name & Option & Frequency & Percentage $(\%)$ \\
\hline \multirow{2}{*}{ Gender } & Male & 135 & 47.04 \\
\hline & Female & 152 & 52.96 \\
\hline \multirow{5}{*}{ Age } & $<25$ & 54 & 18.82 \\
\hline & $26-30$ & 132 & 45.99 \\
\hline & $31-40$ & 84 & 29.27 \\
\hline & $41-50$ & 13 & 4.53 \\
\hline & $>50$ & 4 & 1.39 \\
\hline \multirow{4}{*}{ Education } & High school and below & 5 & 1.74 \\
\hline & Specialist & 39 & 13.59 \\
\hline & Undergraduate & 142 & 49.48 \\
\hline & Master and above & 101 & 35.19 \\
\hline \multirow{4}{*}{ Position } & General Staff & 168 & 58.54 \\
\hline & Grassroots managers & 66 & 23.01 \\
\hline & Middle manager & 48 & 16.72 \\
\hline & Senior management & 5 & 1.73 \\
\hline \multirow{5}{*}{ Length of service } & $<1$ year & 11 & 3.83 \\
\hline & 1-3years & 138 & 48.08 \\
\hline & 4-6years & 87 & 30.31 \\
\hline & 7-9years & 42 & 14.64 \\
\hline & $>10$ years & 9 & 3.14 \\
\hline \multirow{5}{*}{ Unit nature } & Private Enterprise & 139 & 48.43 \\
\hline & State-owned enterprise & 78 & 27.18 \\
\hline & Institutions & 45 & 15.68 \\
\hline & Joint venture & 21 & 7.32 \\
\hline & Foreign companies & 4 & 1.39 \\
\hline
\end{tabular}

\subsection{Reliability and Validity Analysis}

\subsubsection{Reliability Test}

(1) Reliability analysis of perceived trust

As shown in Table 2, the CITC values of 9 items in the 2 dimensions of perceived trust are all greater than 0.6 , indicating that the scale items have a good correlation. Perceived superior dependence and Cronbach's alpha value is 0.853 , and the Cronbach's alpha value revealed by perceptual information is 0.871 , indicating that the reliability of the scale is good.

Table 2. Analysis of Perceived Trust Reliability.

\begin{tabular}{ccccc}
\hline Variable & Item & CITC & $\alpha$ coefficient & Cronbach's $\alpha$ \\
\hline
\end{tabular}




\begin{tabular}{lllll}
\hline & A11 & 0.699 & 0.812 & \\
Perceive Superior Dependence & A12 & 0.684 & 0.818 & 0.853 \\
& A13 & 0.71 & 0.807 & \\
& A14 & 0.689 & 0.817 & \\
\hline \multirow{2}{*}{ Perceptual Information Disclosure } & A21 & 0.651 & 0.855 & 0.871 \\
& A22 & 0.714 & 0.839 & \\
& A23 & 0.73 & 0.835 & \\
& A24 & 0.717 & 0.839 & 0.849 \\
\hline
\end{tabular}

(2) Reliability analysis of psychological empowerment

As shown in Table 3, the CITC values of 12 items in the 4 dimensions of psychological empowerment are all greater than 0.6 , indicating that the scale items have a good correlation coefficient. The Cronbach's $\alpha$ corresponding to the four dimensions of psychological empowerment are all greater than 0.8 , and the Cronbach coefficient is less than the total coefficient, indicating a good level of reliability.

Table 3. Reliability Analysis of Psychological Empowerment.

\begin{tabular}{ccccc}
\hline Variable & Item & CITC & $\alpha$ coefficient & Cronbach's $\alpha$ \\
\hline Significance of work & B11 & 0.701 & 0.790 & 0.843 \\
& B12 & 0.707 & 0.784 & 0.772 \\
Ability & B13 & 0.719 & 0.797 & 0.860 \\
& B21 & 0.741 & 0.802 & \\
\hline Autonomy & B22 & 0.738 & 0.811 & 0.826 \\
& B23 & 0.727 & 0.753 & 0.746 \\
\hline Influence & B31 & 0.689 & 0.779 & 0.833 \\
& B32 & 0.695 & 0.789 & \\
\hline
\end{tabular}

(3) Reliability analysis of work performance

As shown in Table 4, the CITC values of 11 items in the 2 dimensions of work performance are all greater than 0.6 , indicating that the scale items have a good correlation coefficient. The Cronbach's $\alpha$ corresponding to the two dimensions of work performance are both greater than 0.8 , and the Cronbach coefficient is less than the total coefficient, indicating a good level of reliability.

Table 4. Reliability Analysis of Work Performance.

\begin{tabular}{ccccc}
\hline Variable & Item & CITC & $\alpha$ coefficient & Cronbach's $\alpha$ \\
\hline \multirow{3}{*}{ Task performance } & C11 & 0.864 & 0.940 & \\
& C12 & 0.868 & 0.940 & 0.951 \\
& C13 & 0.843 & 0.944 & \\
& C14 & 0.887 & 0.937 & \\
\hline
\end{tabular}




\begin{tabular}{|c|c|c|c|c|}
\hline & $\mathrm{C} 15$ & 0.868 & 0.939 & \\
\hline \multirow{6}{*}{ Relationship performance } & $\mathrm{C} 21$ & 0.801 & 0.908 & \multirow{6}{*}{0.925} \\
\hline & $\mathrm{C} 22$ & 0.782 & 0.908 & \\
\hline & $\mathrm{C} 23$ & 0.782 & 0.904 & \\
\hline & $\mathrm{C} 24$ & 0.784 & 0.908 & \\
\hline & $\mathrm{C} 25$ & 0.787 & 0.911 & \\
\hline & $\mathrm{C} 26$ & 0.779 & 0.902 & \\
\hline
\end{tabular}

\subsubsection{Validity Test}

(1) Validity analysis of perceived trust

As shown in Table 5, a total of 9 items in the two dimensions of perceived trust variables are analyzed for validity. The KMO value of perceptual trust is 0.862 , and the Bartlett sphere test is significant at the level of 0.000 , indicating that the sample data of perceptual trust variables can be subjected to factor analysis.

Table 5. KMO and Bartlett Test of Perceived Trust.

\begin{tabular}{ccc}
\hline Sampling adequacy of KMO metrics & & 0.862 \\
\hline \multirow{2}{*}{ Bartlett sphericity test } & Approximate chi-square & 812.476 \\
& df & 36 \\
& p. & 0.000 \\
\hline
\end{tabular}

Based on the KMO value of the perceived trust variable and the results of Bartlett's sphere test, this study conducted a factor analysis on the perceived trust, and the results are shown in Tables 6 and 7. The total variance of the perceptual trust extraction factor is explained as $67.739 \%(45.426 \%+22.313 \%)$. In the rotation component matrix, two dimensions are extracted by the maximum variance method, which respectively correspond to the perceptual superior dependence of perceptual trust and perceptual information disclosure, which meets the requirements. Therefore, the structural validity of the Perceived Trust Scale is better.

Table 6. Interpretation of the Total Variance of Perceived Trust.

\begin{tabular}{|c|c|c|c|c|c|c|}
\hline \multirow{2}{*}{ Element } & \multicolumn{2}{|c|}{ Initial Eigenvalue } & \multicolumn{2}{|c|}{ Extract the Sum of Squares of the Load } & \multicolumn{2}{|c|}{ Rotating Load Sum of Squares } \\
\hline & Total & Variance $\%$ & Total & Variance $\%$ & Total & Variance $\%$ \\
\hline A11 & 4.088 & 45.426 & 4.088 & 45.426 & 3.295 & 36.608 \\
\hline A12 & 2.008 & 22.313 & 2.008 & 22.313 & 2.802 & 31.131 \\
\hline A13 & 0.554 & 6.155 & & & & \\
\hline A14 & 0.477 & 5.3 & & & & \\
\hline A21 & 0.437 & 4.857 & & & & \\
\hline A22 & 0.407 & 4.524 & & & & \\
\hline $\mathrm{A} 23$ & 0.376 & 4.179 & & & & \\
\hline A24 & 0.364 & 4.042 & & & & \\
\hline A 25 & 0.288 & 3.203 & & & & \\
\hline
\end{tabular}

Table 7. Component Matrix after Perceptual Trust Rotation.

\begin{tabular}{lcccc}
\hline & \multicolumn{2}{c}{ Element } \\
Variable & Item & 1 & 2 \\
\hline
\end{tabular}




\begin{tabular}{llll}
\hline & A11 & 0.820 \\
Perceive Superior Dependence & A12 & 0.835 \\
& A13 & & 0.829 \\
Perceptual Information Disclosure & A14 & & 0.804 \\
& A21 & 0.774 & \\
& A22 & 0.816 & \\
\hline
\end{tabular}

(2) Validity analysis of psychological empowerment

As shown in Table 8, the validity analysis of 12 items in 4 dimensions of psychological empowerment is carried out. Among them, the KMO value and Bartlett sphericity test results are shown in Table 8 . The KMO value of psychological empowerment is 0.833 , and the Bartlett sphere test is significant at the 0.000 level, indicating that the sample data of psychological empowerment variables can be subjected to factor analysis.

Table 8. Psychological Authorization KMO and Bartlett Test.

\begin{tabular}{ccr}
\hline Sampling adequacy of KMO metrics & 0.833 & 1109.732 \\
Bartlett sphericity test & Approximate chi-square & 66 \\
& df & 0.000 \\
\hline
\end{tabular}

Based on the KMO value of the psychological empowerment variable and the Bartlett sphere test result, this study conducted a factor analysis on the psychological empowerment, and the results are shown in Tables 9 and 10. The explanation of the total variance of the psychological empowerment extraction factor is $76.469 \%$. In the rotation component matrix, 4 dimensions are extracted by the maximum variance method, which meet the requirements for the work meaning, ability, autonomy and influence of psychological empowerment respectively. Therefore, the structural validity of the psychological empowerment scale is better.

Table 9. Explanation of Total Variance of Psychological Empowerment.

\begin{tabular}{ccccccc}
\hline \multirow{2}{*}{ Element } & \multicolumn{2}{c}{ Initial Eigenvalue } & \multicolumn{2}{c}{ Extract the Sum of Squares of the Load } & \multicolumn{2}{c}{ Rotating Load Sum of Squares } \\
& Total & Variance\% & Total & Variance\% & Total & Variance\% \\
\hline B11 & 4.708 & 39.232 & 4.708 & 39.232 & 2.328 & 19.4 \\
B12 & 1.769 & 14.742 & 1.769 & 14.742 & 2.321 & 19.341 \\
B13 & 1.506 & 12.549 & 1.506 & 12.549 & 2.284 & 19.036 \\
B21 & 1.194 & 9.946 & 1.194 & 9.946 & & 2.243 \\
B22 & 0.443 & 3.688 & & & & \\
B23 & 0.426 & 3.552 & & & & \\
B31 & 0.384 & 3.197 & & & \\
B32 & 0.362 & 3.021 & & & \\
B33 & 0.346 & 2.882 & & & \\
B41 & 0.314 & 2.619 & & & \\
B42 & 0.292 & 2.431 & & & \\
B43 & 0.257 & 2.141 & & & & \\
\hline
\end{tabular}


Table 10. Component Matrix after Mental Authorization Rotation.

\begin{tabular}{|c|c|c|c|c|c|}
\hline \multirow{2}{*}{ Variable } & \multirow{2}{*}{ Item } & \multicolumn{4}{|c|}{ Element } \\
\hline & & 1 & 2 & 3 & 4 \\
\hline & B11 & & 0.836 & & \\
\hline \multirow[t]{3}{*}{ Significance of work } & $\mathrm{B} 12$ & & 0.864 & & \\
\hline & B13 & & 0.853 & & \\
\hline & B21 & 0.840 & & & \\
\hline \multirow[t]{3}{*}{ Ability } & B22 & 0.840 & & & \\
\hline & B23 & 0.831 & & & \\
\hline & B31 & & & & 0.794 \\
\hline \multirow[t]{3}{*}{ Autonomy } & B32 & & & & 0.824 \\
\hline & B33 & & & & 0.833 \\
\hline & B41 & & & 0.832 & \\
\hline \multirow[t]{2}{*}{ Influence } & B42 & & & 0.836 & \\
\hline & B43 & & & 0.835 & \\
\hline
\end{tabular}

(3) Validity analysis of work performance

As shown in Table 11, the validity analysis is carried out on 11 items in 2 dimensions of work performance. Among them, the KMO value and Bartlett sphericity test results are shown in Table 11. The KMO value of work performance is 0.944 , and the Bartlett sphere test is significant at the level of 0.000 , indicating that the sample data of work performance variables can be factored.

Table 11. KMO and Bartlett Test of Work Performance.

\begin{tabular}{ccc}
\hline Sampling adequacy of KMO metrics & & 0.944 \\
\hline \multirow{2}{*}{ Bartlett sphericity test } & Approximate chi-square & 1824.774 \\
& df & 45 \\
& p. & 0.000 \\
\hline
\end{tabular}

Based on the KMO value of the work performance variables and the Bartlett sphere test results meet the requirements, this study performed factor analysis on work performance, and the results are shown in Tables 12 and 13. The total variance of the work performance extraction factor is explained as $80.712 \%$. In the rotating component matrix, two dimensions are extracted by the maximum variance method, which correspond to the task performance and relationship performance in the secondary dimension of work performance, which meet the requirements. Therefore, the structural validity of the work performance scale is better. The analysis results show that perceived trust, work performance, and psychological empowerment are significantly correlated at the 0.01 level, and the various dimensions of the variables are significantly correlated at the 0.01 level.

Table 12. Explanation of Total Variance of Work Performance.

\begin{tabular}{|c|c|c|c|c|c|c|}
\hline \multirow[t]{2}{*}{ Element } & \multicolumn{2}{|c|}{ Initial Eigenvalue } & \multicolumn{2}{|c|}{$\begin{array}{c}\text { Extract the Sum of Squares of } \\
\text { the Load }\end{array}$} & \multicolumn{2}{|c|}{ Rotating Load Sum of Squares } \\
\hline & Total & Variance $\%$ & Total & Variance $\%$ & Total & Variance $\%$ \\
\hline $\mathrm{C} 11$ & 6.704 & 67.04 & 6.704 & 67.04 & 4.181 & 41.815 \\
\hline $\mathrm{C} 12$ & 1.367 & 13.671 & 1.367 & 13.671 & 3.89 & 38.897 \\
\hline $\mathrm{C} 13$ & 0.339 & 3.386 & & & & \\
\hline $\mathrm{C} 14$ & 0.298 & 2.975 & & & & \\
\hline
\end{tabular}




$\begin{array}{lcc}\text { C15 } & 0.277 & 2.766 \\ \mathrm{C} 21 & 0.262 & 2.617 \\ \mathrm{C} 22 & 0.226 & 2.257 \\ \mathrm{C} 23 & 0.193 & 1.933 \\ \mathrm{C} 24 & 0.18 & 1.803 \\ \mathrm{C} 25 & 0.168 & 1.732 \\ \mathrm{C} 26 & 0.155 & 1.552\end{array}$

Table 13. Component Matrix after Work Performance Rotation

\begin{tabular}{clcc}
\hline Variable & Item & Element & 2 \\
\hline Task Performance & C11 & 0.886 & \\
& $\mathrm{C} 12$ & 0.855 & \\
& $\mathrm{C} 13$ & 0.822 & \\
& $\mathrm{C} 14$ & 0.870 & 0.817 \\
Relationship Performance & $\mathrm{C} 15$ & 0.849 & 0.775 \\
& $\mathrm{C} 21$ & & 0.843 \\
& $\mathrm{C} 22$ & & 0.827 \\
& $\mathrm{C} 23$ & & 0.836 \\
& $\mathrm{C} 24$ & & 0.793 \\
\hline
\end{tabular}

\section{Analysis of the Mediating Role of Psychological Empowerment in Perceived Trust} and Work Performance

\subsection{Regression Analysis of Psychological Empowerment to Work Performance}

Table 14 shows the regression analysis results of various dimensions of psychological empowerment on task performance. The multiple correlation coefficient is 0.800 . The coefficient of determination $\boldsymbol{R}^{2}=0.640$, indicating that the data interpretation degree of mental empowerment to task performance is $64.0 \%$. In the analysis of variance, $F=86.284$ and Sig $=0.000$, indicating that the model is highly significant and statistically significant. In addition, the regression coefficient of work significance is 0.199 , Sig $=0.001$; the regression coefficient of ability is 0.259 , Sig $=0.000$; the regression coefficient of autonomy is 0.506 , $\operatorname{Sig}=0.000$; the regression coefficient of influence is $0.376, \mathrm{Sig}=0.000$. It shows that work meaning, ability, autonomy and influence are positively related to task performance, so the assumptions H1a, H1b, H1c, and H1d are established.

Table 14. Regression Analysis of Various Dimensions of Psychological Empowerment on Task Performance.

\begin{tabular}{|c|c|c|c|c|c|c|c|c|}
\hline \multirow{2}{*}{ Model } & \multicolumn{2}{|c|}{ Model summary } & \multicolumn{2}{|c|}{ Variance analysis } & \multicolumn{2}{|c|}{ Non-standardized coefficient } & \multirow{2}{*}{$t$} & \multirow{2}{*}{ Sig. } \\
\hline & $\boldsymbol{R}$ & $R^{2}$ & $\boldsymbol{F}$ & Sig. & $\boldsymbol{B}$ & Standard error & & \\
\hline (Constant) & & & & & -1.144 & 0.299 & -3.820 & 0.000 \\
\hline $\begin{array}{c}\text { Significance } \\
\text { of work }\end{array}$ & & & & & 0.199 & 0.060 & 3.304 & 0.001 \\
\hline Ability & 0800 & 0640 & 86294 & 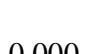 & 0.259 & 0.062 & 4.147 & 0.000 \\
\hline Autonomy & 0.000 & 0.040 & 80.284 & 0.000 & 0.506 & 0.064 & 7.902 & 0.000 \\
\hline Influence & & & & & 0.376 & 0.059 & 6.431 & 0.000 \\
\hline
\end{tabular}


Table 15 shows the regression analysis results on task performance. The multiple correlation coefficient of the relationship performance is 0.626 . The coefficient of determination $R^{2}=0.392$, indicating that the data interpretation rate of psychological empowerment to relational performance is $39.2 \%$. In the analysis of variance, $\boldsymbol{F}=31.332$ and Sig=0.000, indicating that the model is highly significant and statistically significant. In addition, the regression coefficient of work meaning is 0.115 , Sig $=0.080$, indicating that there is no significant relationship between work meaning and relationship performance; the regression coefficient of ability is 0.294, Sig=0.000; the regression coefficient of autonomy is 0.097, Sig $=0.162$, indicating that there is no significant relationship between autonomy and relationship performance; the regression coefficient of influence is $0.350, S i g=0.000$. It shows that influence is positively correlated with relationship performance, so suppose H1f and H1h are valid, but H1e and H1g are not valid.

Table 15. Regression Analysis of Various Dimensions of Psychological Empowerment on Relationship Performance.

\begin{tabular}{|c|c|c|c|c|c|c|c|c|}
\hline \multirow{2}{*}{ Model } & \multicolumn{2}{|c|}{ Model summary } & \multicolumn{2}{|c|}{ Variance analysis } & \multicolumn{2}{|c|}{ Non-standardized coefficient } & \multirow{2}{*}{$t$} & \multirow{2}{*}{ Sig. } \\
\hline & $\boldsymbol{R}$ & $R^{2}$ & $\boldsymbol{F}$ & Sig. & $\boldsymbol{B}$ & Standard error & & \\
\hline (Constant) & & & & & 0.607 & 0.324 & 1.875 & 0.062 \\
\hline $\begin{array}{c}\text { Significance } \\
\text { of work }\end{array}$ & & & & & 0.115 & 0.065 & 1.761 & 0.080 \\
\hline Ability & orar & 0000 & 010 & 000 & 0.294 & 0.068 & 4.344 & 0.000 \\
\hline Autonomy & 0.026 & 0.392 & 31.332 & 0.000 & 0.097 & 0.069 & 1.403 & 0.162 \\
\hline Influence & & & & & 0.350 & 0.063 & 5.521 & 0.000 \\
\hline
\end{tabular}

The analysis results are shown in Table 16. The multiple correlation coefficient is 0.787; the determination coefficient $R^{2}=0.620$ indicates that the data interpretation degree of perceived trust on work performance is $62.0 \%$; in the analysis of variance, $F=320.877$, Sig $=0.000$, indicating that the model is highly significant and statistically significant. In addition, the regression coefficient of psychological empowerment is 1.240, Sig=0.000, indicating that the hypothesis $\mathrm{H} 1$ is established.

Table 16. Regression Analysis of Psychological Empowerment to Work Performance.

\begin{tabular}{|c|c|c|c|c|c|c|c|c|}
\hline \multirow{2}{*}{ Model } & \multicolumn{2}{|c|}{ Model summary } & \multicolumn{2}{|c|}{ Variance analysis } & \multicolumn{2}{|c|}{ Non-standardized coefficient } & \multirow{2}{*}{$t$} & \multirow{2}{*}{ Sig. } \\
\hline & $\boldsymbol{R}$ & $R^{2}$ & $\boldsymbol{F}$ & Sig. & $\boldsymbol{B}$ & Standard error & & \\
\hline (Constant) & & & & & -0.382 & 0.275 & -1.387 & 0.167 \\
\hline $\begin{array}{l}\text { Psychological } \\
\text { empowerment }\end{array}$ & 0.787 & 0.620 & 320.877 & 0.000 & 1.240 & 0.069 & 17.913 & 0.000 \\
\hline
\end{tabular}

5.2. Mediating Role of Psychological Empowerment in the Perception of Superior Dependence and Work Performance

As shown in Table 17, Model 1: Perceived superiors rely on regression analysis of task performance. The coefficient of determination $R^{2}=0.263, F=70.356$, and Sig=0.000, indicating that the model is highly significant. The regression coefficient of perceived trust is $0.679(\boldsymbol{P}=0.000)$, and the regression effect is significant. Model 2: Regression analysis of psychological empowerment to task performance. The coefficient of determination $\boldsymbol{R}^{2}=0.616, \boldsymbol{F}=316.535$, and Sig=0.000, indicating that the model is highly significant; the regression coefficient of psychological empowerment is $1.360(\boldsymbol{P}=0.000)$. Model 3: Regression analysis of perceived superior dependence and psychological empowerment on task performance. The coefficient of determination of the model is $R^{2}=0.653, F=184.093$, and Sig $=0.000$, indicating that the model is highly significant. The regression coefficient of psychological empowerment is 1.200, the regression coefficient of perceiving superior 
dependence is 0.280 , and the significance level has not changed. It shows that the hypothesis H1a holds.

Table 17. Test of the Mediating Effect of Psychological Empowerment between Perceived Superior Dependence and Task Performance.

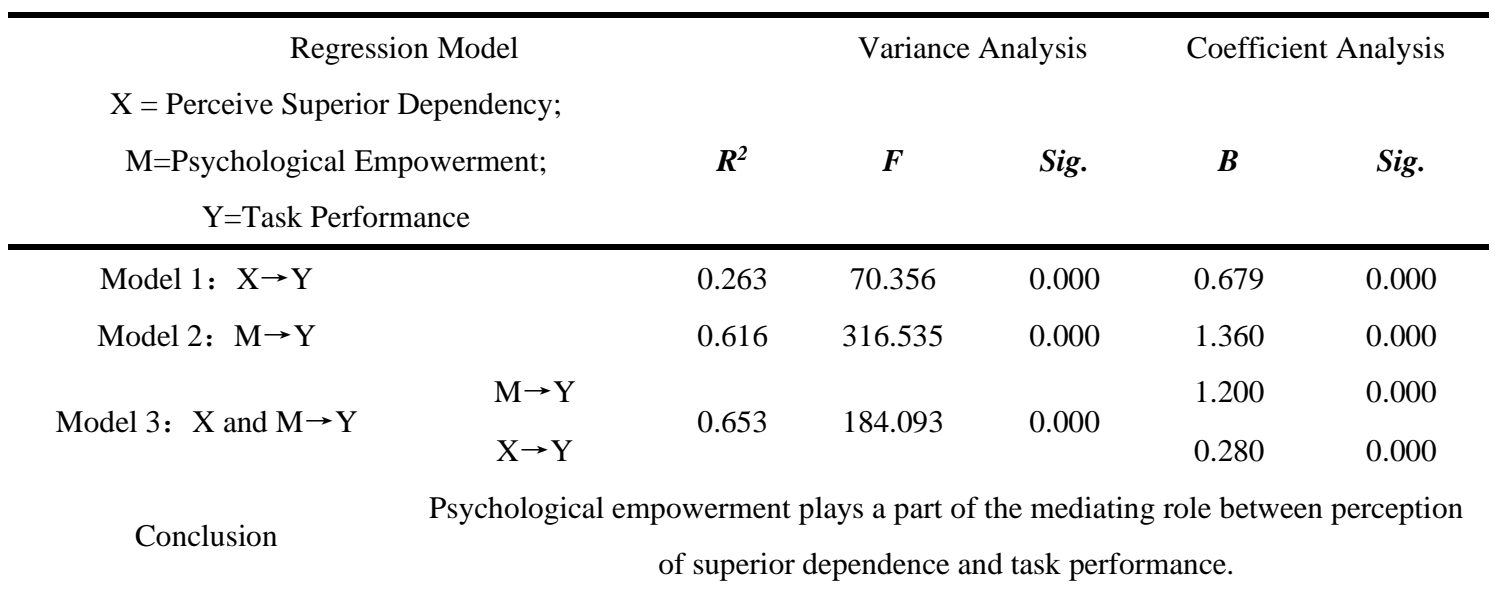

As shown in Table 18, Model 1: Perceived superior dependence on the regression analysis of relationship performance. The coefficient of determination $\boldsymbol{R}^{2}=0.282, \boldsymbol{F}=77.513$, Sig $=0.000$, indicating that the model is highly significant, the regression coefficient of perceived trust is $0.586(P=0.000)$, and the regression effect is significant. Model 2: Regression analysis of psychological empowerment to relationship performance. The coefficient of determination $\boldsymbol{R}^{2}=0.366, F=113.832$, and Sig=0.000, indicating that the model is highly significant; the regression coefficient of psychological empowerment is $0.873(\boldsymbol{P}=0.000)$. Model 3: Regression analysis of perceived superior dependence and psychological empowerment on relationship performance. The coefficient of determination of the model is $\boldsymbol{R}^{2}=0.455, \boldsymbol{F}=81.764$, and Sig=0.000, indicating that the model is highly significant. The regression coefficient is 0.665 , the regression coefficient of perceiving superior dependence is 0.365 , and the significance level has not changed, so hypothesis H1b holds.

Table 18. Test of the Mediating Effect of Psychological Empowerment between Perceived Superior Dependence and Relationship Performance.

\begin{tabular}{|c|c|c|c|c|c|c|}
\hline \multicolumn{3}{|c|}{ Regression Model } & \multicolumn{2}{|c|}{ Variance Analysis } & \multicolumn{2}{|c|}{ Coefficient Analysis } \\
\hline $\begin{array}{r}\mathrm{X}=\text { Perceive Superio } \\
\text { M=Psychological E } \\
\text { Y=Relational Pe }\end{array}$ & $\begin{array}{l}\text { Pependency; } \\
\text { owerment; } \\
\text { rmance }\end{array}$ & $R^{2}$ & $F$ & Sig. & $B$ & Sig. \\
\hline Model 1: $X \rightarrow Y$ & & 0.282 & 77.513 & 0.000 & 0.586 & 0.000 \\
\hline Model 2: $\mathrm{M} \rightarrow \mathrm{Y}$ & & 0.366 & 113.832 & 0.000 & 0.873 & 0.000 \\
\hline Model 3: $\mathrm{X}$ and $\mathrm{M} \rightarrow \mathrm{Y}$ & $\begin{array}{l}M \rightarrow Y \\
X \rightarrow Y\end{array}$ & 0.455 & 81.764 & 0.000 & $\begin{array}{l}0.665 \\
0.365\end{array}$ & $\begin{array}{l}0.000 \\
0.000\end{array}$ \\
\hline Conclusion & Psychologica & $\begin{array}{l}\text { wermen } \\
\text { erior de }\end{array}$ & $\begin{array}{l}\text { ays a part } \\
\text { dence and }\end{array}$ & $\begin{array}{l}\text { e mediati } \\
\text { tionship }\end{array}$ & $\begin{array}{l}\text { ole betw } \\
\text { ormance }\end{array}$ & rception \\
\hline
\end{tabular}

5.3. Mediating Role of Psychological Empowerment between Perceived Information Disclosure and Work Performance

As shown in Table 19, Model 1: Regression analysis of perceptual information disclosure on task performance. The coefficient of determination $\boldsymbol{R}^{2}=0.322, F=93.482$, and Sig $=0.000$, indicating that the model is highly significant, the regression coefficient of perceived trust is $0.786(P=0.000)$, and the regression effect is significant. Model 2: Regression analysis of psychological empowerment to task performance. The coefficient of 
determination $\boldsymbol{R}^{2}=0.616, F=316.535$, and $\operatorname{Sig}=0.000$, indicating that the model is highly significant; the regression coefficient of psychological empowerment is $1.360(\boldsymbol{P}=0.000)$. Model 3: Regression analysis of perceptual information disclosure and psychological authorization on task performance. The coefficient of determination of the model is $R^{2}=0.660$, $F=190.472$, and Sig=0.000, indicating that the model is highly significant. The regression coefficient of psychological empowerment is 1.156, the regression coefficient of perceptual information disclosure is 0.333 , and the significance level has not changed, indicating that psychological empowerment plays a part of the mediating role between perceptual information disclosure and task performance, so hypothesis H1c is established.

Table 19. Test of the Mediating Effect of Psychological Empowerment between Perceived Information Disclosure and Task Performance.

\begin{tabular}{|c|c|c|c|c|c|c|}
\hline \multicolumn{3}{|c|}{ Regression Model } & \multicolumn{2}{|c|}{ Variance Analysis } & \multicolumn{2}{|c|}{ Coefficient Analysis } \\
\hline $\begin{array}{r}\mathrm{X}=\text { Disclosure of Perce } \\
\mathrm{M}=\text { Psychological } \\
\mathrm{Y}=\text { Task Perf }\end{array}$ & $\begin{array}{l}\text { Information } \\
\text { werment; }\end{array}$ & $R^{2}$ & $F$ & Sig. & $\boldsymbol{B}$ & Sig. \\
\hline Model 1: $X \rightarrow Y$ & & 0.322 & 93.482 & 0.000 & 0.786 & 0.000 \\
\hline Model 2: $\mathrm{M} \rightarrow \mathrm{Y}$ & & 0.616 & 316.535 & 0.000 & 1.360 & 0.000 \\
\hline Model 3: $\mathrm{X}$ and $\mathrm{M} \rightarrow \mathrm{Y}$ & $\begin{array}{l}M \rightarrow Y \\
X \rightarrow Y\end{array}$ & 0.660 & 190.472 & 0.000 & $\begin{array}{l}1.156 \\
0.333\end{array}$ & $\begin{array}{l}0.000 \\
0.000\end{array}$ \\
\hline Conclusion & Psychologi & formati & $\begin{array}{l}\text { ays a part } \\
\text { lisclosure }\end{array}$ & $\begin{array}{l}\text { e media } \\
\text { ask perf }\end{array}$ & $\begin{array}{l}\text { role betw } \\
\text { ance. }\end{array}$ & erceived \\
\hline
\end{tabular}

As shown in Table 20, Model 1: Regression analysis of perceptual information disclosure on relationship performance. The coefficient of determination $R^{2}=0.311, F=89.085$, and Sig $=0.000$, indicating that the model is highly significant, the regression coefficient of perceived trust is $0.643(\boldsymbol{P}=0.000)$, and the regression effect is significant. Model 2: Regression analysis of psychological empowerment to relationship performance. The coefficient of determination $\boldsymbol{R}^{2}=0.366, F=113.832$, and Sig=0.000, indicating that the model is highly significant; the regression coefficient of psychological empowerment is $0.873(\boldsymbol{P}=0.000)$. Model 3: Regression analysis of perceptual information disclosure and psychological empowerment on relationship performance. The coefficient of determination of the model is $\boldsymbol{R}^{2}=0.456, \boldsymbol{F}=82.222$, and Sig=0.000, indicating that the model is highly significant. The regression coefficient is 0.629 , the regression coefficient of perceptual information disclosure is 0.397 , and the significance level has not changed, indicating that psychological empowerment plays a part of the mediating role between perceptual information disclosure and relationship performance, so the hypothesis H1d holds.

Table 20. Test of the Mediating Effect of Psychological Empowerment between Perceived Information Disclosure and Relationship Performance.

Regression Model
$\begin{gathered}\mathrm{X}=\text { Disclosure of Perception Information; } \\ \text { M=Psychological Empowerment; } \\ \text { Y=Relational Performance }\end{gathered}$




\subsection{Mediating Role of Psychological Empowerment between Perceived Trust and Work Performance}

As shown in Table 21, Model 1: Regression analysis of perceived trust on Work performance. The coefficient of determination $R^{2}=0.554, F=244.646$, and Sig=0.000, indicating that the model is highly significant, the regression coefficient of perceived trust is 1.123 $(\boldsymbol{P}=0.000)$, and the regression effect is significant. Model 2: Regression analysis of psychological empowerment to Work performance. The coefficient of determination $\boldsymbol{R}^{2}=0.620$, $F=320.877$, and Sig=0.000, indicating that the model is highly significant; the regression coefficient of psychological empowerment is $1.240(\boldsymbol{P}=0.000)$. Model 3: Regression analysis of perceived trust and psychological empowerment on Work performance. The coefficient of determination of the model is $R^{2}=0.750, F=293.684$, and $S i g=0.000$, indicating that the model is highly significant. The regression coefficient of psychological empowerment is 0.847 , the regression coefficient of perceived trust is 0.662 , so hypothesis H1 is established.

Table 21. Test of the Mediating Effect of Psychological Empowerment between Perceived Trust and Work Performance.

\begin{tabular}{|c|c|c|c|c|c|c|}
\hline \multicolumn{3}{|c|}{ Regression Model } & \multicolumn{2}{|c|}{ Variance Analysis } & \multicolumn{2}{|c|}{ Coefficient Analysis } \\
\hline \multicolumn{2}{|c|}{$\begin{array}{c}\mathrm{X}=\text { Perceived Superior Trust; } \\
\text { M=Psychological Empowerment; } \\
\text { Y=Work Performance }\end{array}$} & $R^{2}$ & $\boldsymbol{F}$ & Sig. & $\boldsymbol{B}$ & Sig. \\
\hline Model 1: $X \rightarrow Y$ & & 0.544 & 244.646 & 0.000 & 1.123 & 0.000 \\
\hline Model 2: $\mathrm{M} \rightarrow \mathrm{Y}$ & & 0.620 & 320.877 & 0.000 & 1.240 & 0.000 \\
\hline Model 3: $\mathrm{X}$ and $\mathrm{M} \rightarrow \mathrm{Y}$ & $\begin{array}{l}M \rightarrow Y \\
X \rightarrow Y\end{array}$ & 0.750 & 293.684 & 0.000 & $\begin{array}{l}0.847 \\
0.662\end{array}$ & $\begin{array}{l}0.000 \\
0.000\end{array}$ \\
\hline Conclusion & Psycholo & $\begin{array}{r}\text { powerm } \\
\text { of } \mathrm{st}\end{array}$ & $\begin{array}{l}\text { ays a part } \\
r \text { trust and }\end{array}$ & mediat & $\begin{array}{l}\text { ole betwe } \\
\text { e. }\end{array}$ & erception \\
\hline
\end{tabular}

\section{Conclusions}

This paper explores the mechanism and influence of psychological empowerment in perceived trust and work performance from the perspective of employees, and chooses to set the independent variable as the employee's perceived trust and the dependent variable as the company's work performance, and explores the mediating role of psychological empowerment in the two. In the study of perceived trust and work performance, this article focuses on the mediating role of psychological empowerment, and further understands the internal mechanism of perceived trust. The conclusions reached are as follows:

(1) The psychological empowerment of employees has a positive impact on work performance. This result shows that employees with very obvious psychological empowerment have a higher evaluation of their ability to solve problems at work, are often proactive in their work, and have more investment in work, which in turn promotes employees to have higher work performance. The four dimensions of psychological empowerment can positively affect employee task performance, and the ability and influence of psychological empowerment have a great positive impact on relationship performance.

(2) As a whole perception, psychological empowerment plays a part of the mediation role between perception of superior dependency and task performance, and it plays a part of the mediation role between perception of superior dependency and relationship performance. This result indicates that employees who perceive superior dependence and information disclosure have enhanced their perception, and the enhancement of 
perception of psychological empowerment further encourages employees to complete task performance.

(3) As a whole perception, psychological empowerment plays a part of the mediation between perceived information disclosure and task performance, and part of mediation between perceived information disclosure and relationship performance. This result shows that when employees feel the trust of their superiors, their work status is often positively affected, and the effect of this trust and self-perceived trust is obvious.

\section{References}

1. Morgan R M, Hunt S D. The Commitment-Trust Theory of Relationship Marketing[J]. Journal of Marketing, 1994, 58(3):20-38.

2. Mishra J, Morrissey M A. Trust in Employee/Employer Relationships: A Survey of West Michigan Managers[J]. Public Personnel Management, 2000, 19(4):443-486.

3. Brower, H. H., Schoorman, F. D., \& Tan, H. H. A model of relational leadership: The integration of trust and leader-member exchange. The Leadership Quarterly, 2000, 11 (2): 227-250.

4. Haq M, Ahmed M A, Khalid S, et al. Effect of empowering leadership on knowledge sharing: mediating roles of psychological empowerment and psychological capital[J]. International Journal of Knowledge and Learning, 2021, $14(3): 244$.

5. Conger J A, Kanungo R N. The Empowerment Process: Integrating Theory and Practice[J]. Academy of Management Review, 1988, 13(3): 471-482.

6. Kraimer M L, Seibert S E, Liden R C. Psychological Empowerment as a Multidimensional Construct: A Test of Construct Validity[J]. Educational and Psychological Measurement, 1999, 59(1): 127-142.

7. Li C P, Li X X, Shi K, et al. Psychological Empowerment: Measurement and its Effect on Employee Work Attitude in China[J]. Acta Psychologica Sinica, 2006, 38(1): 99-106.

8. Lei Q L, Zhao G S, Duan X M. Research on the relationship of different corporate cultures and knowledge-worker's psychological empowerment[J]. Science Research Management, 2006, (5): 117-123.

9. Javed B, Abdullah I, Zaffar M A, et al. Inclusive leadership and innovative work behavior: The role of psychological empowerment[J]. Journal of Management \& Organization, 2019, 25(4): 554-571.

10. Muhammad S, Ali W, Khalid R, et al. Inclusive Leadership and Project Success: The Mediation Role of Psychological Empowerment and Psychological Resilience Capacity[J]. Psychology (Savannah, Ga.), 2021, 58(1): 5546-5558.

11. Jafari F, Salari N, Hosseinian-Far A, et al. Predicting positive organizational behavior based on structural and psychological empowerment among nurses[J]. Cost Effectiveness and Resource Allocation, 2021, 19(38): 1-9.

12. $\mathrm{Wu} \mathrm{Z} \mathrm{M,} \mathrm{Wu} \mathrm{X.} \mathrm{Transformational} \mathrm{leadership} \mathrm{and} \mathrm{organizational} \mathrm{citizenship} \mathrm{behavior:} \mathrm{Mediating} \mathrm{role} \mathrm{of} \mathrm{psychological} \mathrm{empow-}$ erment[J]. Journal of Management Sciences in China, 2007, 10(5): 40-47.

13. Bowen D E, Lawler E E. The Empowerment of Service Workers: What, Why, How, and When[J]. Sloan management review, 1992, 33(3):31-39.

14. Wang G, Zheng Q. Psychological Empowerment as the Moderator of the Relationship between Psychological Climate and Job Performance[J]. Psychological Science, 2008, 31(2): 294-298.

15. Chen H, Yan S F. The Effect of Work Values of New Generation Employees and the Psychological Empowerment on Job Performance-The Empirical Research based on the Knowledge-based Enterprises[J]. Science \& Technology and Economy, 2014, 27(02): 71-75.

16. Thomas K W, Velthouse B A. Cognitive Elements of Empowerment: An "Interpretive" Model of Intrinsic Task Motivation[J]. The Academy of Management Review, 1990, 15(4):666-681.

17. Costigan R D, Berman S S I J. A Multi-Dimensional Study of Trust in Organizations[J]. Journal of Managerial Issues, 1998, 10(3): 303-317.

18. Rousseau D M, Sitkin S B, Burt R S, et al. Not So Different After All: A Cross-Discipline View Of Trust[J]. Academy of Management Review, 1998, 23(3): 393-404.

19. Lau D C, Liu J, Ping P F. Feeling trusted by business leaders in China: Antecedents and the mediating role of value congruence[J]. Asia Pacific Journal of Management, 2007, 24(3): 321-340.

20. Sun Y L, Kim Y, Kim Y. Engaging consumers with corporate social responsibility campaigns: The roles of interactivity, psychological empowerment, and identification[J]. Journal of Business Research, 2021, 134(4): 507-517.

21. Deci E L, Ryan R M. The "What" and "Why" of Goal Pursuits: Human Needs and the Self-Determination of Behavior[J]. Psychological Inquiry, 2000, 11(4): 227-268.

22. Melinda J. Moye Alan B. Henkin. Exploring associations between employee empowerment and interpersonal trust in managers. Journal of Management Development, 2006, 25(2): 101-117.

23. M.D. Fulford, Enz C A. The Impact Of Empowerment On Service Employees[J]. Journal of Managerial Issues, 1995, 7(2): 161175.

24. Ugwu F O, Onyishi I E, Rodriguez-Sanchez A M. Linking organizational trust with employee engagement: the role of psychological empowerment[J]. Personnel Review, 2014, 43(3): 377-400(24).

25. Prabha M, Punniyamoorthy M, Nivethitha S. Examining the bi-directional relationship between motivation and satisfaction: based on the impact of psychological empowerment[J]. International Journal of Process Management and Benchmarking, 2021, 11(3): 431. 
26. Tariq I, Asad M S, Majeed M A, et al. Work-Family Conflict, Psychological Empowerment, and Turnover Intentions among Married Female Doctors[J]. Bangladesh Journal of Medical Science, 2021, 20(4): 855-863.

27. Hoven A, Mahembe B, Hamman-Fisher D. The influence of servant leadership on psychological empowerment and organisational citizenship on a sample of teachers[J]. SA Journal of Human Resource Management, 2021, 19(9): 1-12.

28. Shafait Z, Zhu Y, Sahibzada U F. Emotional intelligence and conflict management: an execution of organisational learning, psychological empowerment and innovative work behaviour in Chinese higher education[J]. Middle East J of Management, 2021, 8(1): 1 .

29. Dajani M, Mostafa B A. The Impact of COVID-19 Pandemic on Egyptian Women Psychological Empowerment and Work-Life Balance[J]. Journal of Business Administration Research, 2021, 10(1): 20.

30. Bharadwaja M, Tripathi N. Linking empowering leadership and job attitudes: The role of psychological empowerment[J]. Journal of Asia Business Studies, 2021, 15(1): 110-127.

31. Toylan N V, Ylmaz N. The Relationships Between Psychological Empowerment Organizational Trust and Employee Motivation: An Empirical Research on Hotel Employees in Istanbul[J]. Journal of Tourism and Gastronomy Studies, 2021, 9(1): 111130.

32. Di Ab E H, Ebrahim R. Perceiving Psychological Empowerment and Its Relationship to Clinical Competence and Professional Values among Nursing Intern Students[J]. Egyptian Journal of Health Care, 2021, 12(1): 948-972.

33. Llorente-Alonso M, C García-Ael, Topa G, et al. Can Psychological Empowerment Prevent Emotional Disorders in Presence of Fear of COVID-19 in Health Workers? A Cross-Sectional Validation Study[J]. Journal of Clinical Medicine, $2021,10(8): 1614$.

34. Tripathi N, Bharadwaja M. Empowering Leadership and Psychological Health: The Mediating Role of Psychological Empowerment[J]. Employee Responsibilities and Rights Journal, 2020, 32(3): 97-121.

35. Liao K, Deng X, Liao Y, et al. Supplier Empowerment: Mediating Situational Factors and Perceived Performance[J]. Journal of Purchasing and Supply Management, 2020, 26(3): 100611. 